\title{
Using plant wax markers to estimate the diet composition of grazing Holstein dairy cows
}

\author{
C. Heublein, ${ }^{*} †$ K.-H. Südekum,† F. L. Gill,ł F. Dohme-Meier, ${ }^{*}$ and F. Schori ${ }^{* 1}$ \\ ${ }^{*}$ Agroscope, Institute for Livestock Sciences, Tioleyre 4, 1725 Posieux, Switzerland \\ †University of Bonn, Institute of Animal Science, Endenicher Allee 15, 53115 Bonn, Germany \\ łUniversity of Leeds, School of Earth and Environment, LS2 9JT, Leeds, United Kingdom
}

\begin{abstract}
The objective of this study was to test whether diet selection of dairy cows under grazing conditions could be estimated using plant wax markers. Furthermore, differences between 2 cow strains and the effect of concentrate supplementation on plant species selection were investigated. The experiment was a study with a crossover design performed on an organic farm with 12 Swiss Holstein cows and 12 New Zealand Holstein cows. Both experimental periods consisted of a 21-d adaptation and a 7-d measurement period. All cows grazed full time in a rotational stocking system and received either no concentrate or $6 \mathrm{~kg} / \mathrm{d}$ of a commercial cereal-grain mix. Representative herbage samples of each grazed paddock were taken and botanical composition of subsamples was manually determined. The average proportions of the plant species were $27.8 \%$ Lolium perenne, 6.1\% Dactylis glomerata, $10.4 \%$ Trifolium repens, and 9.0\% Taraxacum officinale. Other grass species were merged as "other grass" (38.2\%) and other forb species as "other forbs" (8.5\%). n-Alkanes, long-chain fatty acids, and long-chain alcohols ( $\mathrm{LCOH})$ were analyzed in the samples of plant species, concentrate, and feces from each cow. A linear discriminant analysis indicated that diet components were differentiated best with $\mathrm{LCOH}(96 \%)$ and worst with the combination of all marker groups together (12\%). For each marker, the fecal marker recovery (FR) relative to dosed ytterbium was determined in 2 ways. Estimation of diet composition was performed with the software "EatWhat," and results were compared with botanical composition with the Aitchison distance. The results indicate that the diet composition of grazing dairy cows can be estimated using plant wax markers. Additionally, the calculation of FR led to mostly reliable results, yet this approach needs further validation. The most accurate estimation
\end{abstract}

Received May 20, 2016.

Accepted October 17, 2016.

${ }^{1}$ Corresponding author: fredy.schori@agroscope.admin.ch was achieved with the marker combination of $n$-alkanes and $\mathrm{LCOH}$ with a correction for FR. Less accurate estimations were achieved with long-chain fatty acids alone or in combination with n-alkanes. No difference relating to diet selection between the 2 cow strains was recorded, but supplemented cows apparently ingested higher proportions of $T$. repens than nonsupplemented cows. Awareness that supplementation influences selection behavior of grazing dairy cows may lead to adaptations in botanical composition of the pasture according to the demand of the animals.

Key words: alkane, long-chain fatty acid, long-chain alcohol, concentrate supplementation

\section{INTRODUCTION}

The benefits of grassland communities with a higher diversity of species and functional groups, such as higher productivity, increased resources utilization, higher uptake of nitrogen, and increased occupation of available space, are well known (Spehn et al., 2005). Recently, the considerable features of multi-species, legume-based grassland-livestock systems at different stages in the soil-plant-animal-atmosphere system were summarized by Lüscher et al. (2014). They stated that legume-based grassland-livestock systems would constitute one of the pillars for more sustainable and competitive ruminant production systems and will become more important in the future.

Concentrate supplementation of dairy cows in a pasture-based feeding system causes substitution of herbage and grazing time is reduced [McCarthy et al., 2007; C. Heublein, F. Dohme-Meier, K.-H. Südekum, R. M. Bruckmaier (Vetsuisse Faculty, Bern, Switzerland), S. Thanner (Agroscope, Posieux, Switzerland), and F. Schori, unpublished data], but no certainties exist about whether it influences plant species selection in multispecies pastures. According to Villalba et al. (2015), the knowledge of the effects of feed context on preference of grazing animals should pioneer innovative management strategies to enhance forage intake, pro- 
ductivity, and animal welfare. Previous studies examined the suitability of different cow strains or breeds for a pasture-based feeding system [McCarthy et al., 2007; Piccand et al., 2013; C. Heublein, F. Dohme-Meier, K.-H. Südekum, R. M. Bruckmaier (Vetsuisse Faculty, Bern, Switzerland), S. Thanner (Agroscope, Posieux, Switzerland), and F. Schori, unpublished data], but to the authors' knowledge, no studies considered differences in diet selection on pasture. In New Zealand, Holstein cows are bred for an efficient use of pasture and have a higher feeding drive (McCarthy et al., 2007). Therefore, differences might exist in plant species selection between New Zealand and other Holstein cow strains. Such investigations are needed in natural grazing situation with a greater number of plant species, as requested by Villalba et al. (2015).

Plant wax markers, such as $n$-alkanes (hereafter called alkanes), long-chain fatty acids (LCFA), and long-chain alcohols (LCOH), are used for diet composition estimation of grazing ruminants (Ali et al., 2005; Lin et al., 2012). With the combination of alkanes and LCFA (Ferreira et al., 2009, 2011) or with alkanes and $\mathrm{LCOH}$ (Boland et al., 2012; Ferreira et al., 2015), diet composition estimations provided reasonable results for diets with between 2 and 6 components. The combination of all 3 marker groups might be applicable to situations with more complex diets (Ferreira et al., 2015). Supplementary feeds, such as concentrates, can be labeled and considered as an additional component in the diet (Dove and Charmley, 2008; Elwert et al., 2008). However, several studies included shrubs (Ali et al., 2005) or heather-gorse plant species (Ferreira et al., 2015) in the diets, which are not typical plant species occurring on pastures for dairy cows. Various grasses, legumes, and forbs are the main plants growing on pastures grazed by dairy cows, and studies to estimate plant species selection on multispecies pastures with dairy cows are rare. In one of the few studies on this kind of multispecies pasture, using alkanes alone led to erroneous diet composition estimations of dairy cows (Schori et al., 2012). Therefore, we tested whether the approach of estimating diet composition of grazing dairy cows using plant wax markers is applicable under farming conditions and if reasonable results are obtained with different breeds and concentrate supplementation.

The basic precondition for estimating diet selection of ruminants on a multispecies pasture is the sufficient differentiation of marker profiles between plant species. Identification of markers that contribute most to the differentiation between plant species may reduce workload and contribute to a more accurate differentiation as low concentration of markers and large withinspecies variation may limit their use for diet estimation
(Mayes and Dove, 2000). As the recovery of the markers in the feces is incomplete, an important element for gaining accuracy of diet composition estimation is the fecal recovery (FR) correction (Ferreira et al., 2015). Corrections are needed for incomplete FR of alkanes (Dove and Mayes, 1991), LCFA (Ferreira et al., 2009), and $\mathrm{LCOH}$ (Ferreira et al., 2015), but in the aforementioned studies, FR was determined in indoor feeding experiments with similar diet composition to outdoors, with known amount of DMI, diet composition, and collection of total fecal output. This approach is labor intensive and expensive, so 2 alternative ways for calculating FR were used in the current study. The aim of the study was to test whether the approach using calculated FR to estimate diet selection of dairy cows is applicable under grazing conditions and to investigate which marker group or marker group combination, with or without FR correction, delivers the most accurate estimation. Furthermore, differences between 2 cow strains and the effect of concentrate supplementation on plant species selection were investigated.

\section{MATERIALS AND METHODS}

\section{Experimental Design and Animals}

All experimental procedures were in accordance with the Swiss guidelines for animal welfare and were approved (no. 2012_51_FR) by the Animal Care Committee of the Canton of Fribourg, Switzerland. Before selecting the cows for the experiment, a medical checkup including vital parameters as well as udder and claw health was performed. The experiment was a $2 \times 2$ factorial design, which was conducted as a crossover design with 2 concentrate levels and 2 cow strains. It was divided into 2 measurement periods, each consisting of a 21-d adaption period and a 7-d data collection period (Figure 1). For the flow of work and equipment reasons, the cows were equally divided into 2 consecutive data collection periods of $7 \mathrm{~d}$ per measurement period, resulting in 4 data collection periods. The experiment took place on the organic farm "Ferme École de Sorens" located $824 \mathrm{~m}$ above sea level in Sorens, Switzerland.

A total of 24 Holstein cows, including 12 Swiss Holstein cows $(\mathbf{H C H})$ and 12 Holstein cows of New Zealand origin (HNZ), were used for the experiment. Sixteen of them were multiparous and 8 were primiparous. Matched pairs of $\mathrm{HCH}$ and HNZ cows were formed according to the number of lactation and DIM for multiparous cows. For primiparous cows, age was considered beside DIM. At the start of the first data collection period, $\mathrm{HCH}$ cows had an average number of lactations of 2.1 (SD 1.0), had been 101 (SD 23.7) DIM, had an average BW of 580 (SD 56.3) kg, a BCS of 2.6 
$\boldsymbol{Z}=$ Adaptation period, step-wise adaptation of the concentrate ( 0 or $6 \mathrm{~kg} / \mathrm{d}$ ).

目 = Adaptation period, labeled barley was included in the concentrate ration ( $10 \%$ of the $6 \mathrm{~kg} / \mathrm{d})$. $\square=$ Data collection period.

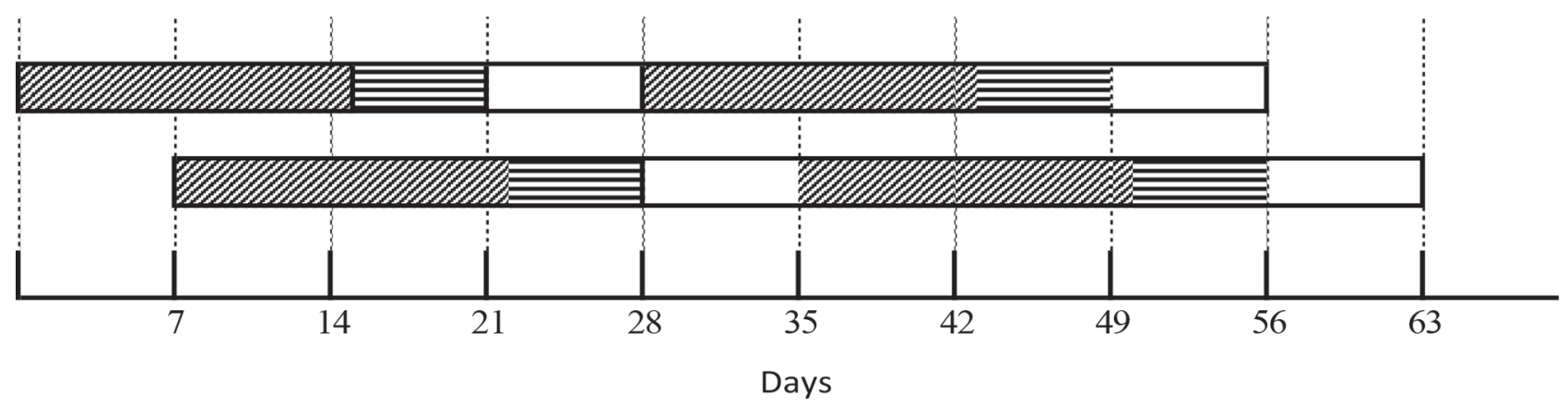

Figure 1. Description of the experiment setup.

(SD 0.31), and were producing 34.9 (SD 6.08) $\mathrm{kg}$ of milk/d. The HNZ cows had an average number of lactations of 2.1 (SD 1.0), had been 102 (SD 22.0) DIM, had an average BW of 513 (SD 75.5) kg, a BCS of 2.8 (SD 0.25 ), and were producing 29.1 (SD 4.44) $\mathrm{kg}$ of milk/d.

During the first measurement period, one of the supplemented $\mathrm{HCH}$ cows was excluded from the experiment because of health problems.

\section{Grazing Management, Pasture, and Weather Conditions}

The experiment was carried out in a rotational grazing system from May 6 to July 14 in 2013. All 24 experimental dairy cows were managed as a single herd and grazed on pasture from 0800 to $1400 \mathrm{~h}$ and from 1800 to $0430 \mathrm{~h}$ the following morning. In the meantime, cows were housed in a freestall barn. For certain work steps, cows were briefly tethered in the cubicles. Indoors, cows had no access to roughages, but concentrate was distributed to supplemented cows. Cows were milked twice a day at $0500 \mathrm{~h}$ in the morning and $1600 \mathrm{~h}$ in the afternoon. Paddocks used were rotationally grazed for 1 to $5 \mathrm{~d}$ based on decision rules considering sward height with a reference of 130 $\mathrm{mm}$ pre-grazing equivalent to an herbage mass of approximately $1,000 \mathrm{~kg}$ of $\mathrm{DM} / \mathrm{ha}$ above $50 \mathrm{~mm}$ until a postgrazing sward height of $50 \mathrm{~mm}$ from ground level. The sward surface height was measured with a pasture meter (C-Dax pasture meter, C-Dax Ltd., Turitea, New Zealand) before cows entered a new paddock and after leaving the paddock. The average pre-grazing sward height was $72(\mathrm{SD} 6.6 ; \mathrm{n}=10) \mathrm{mm}$, corresponding to 295 (SD 84.5) $\mathrm{kg}$ of $\mathrm{DM} / \mathrm{ha}$ above $50 \mathrm{~mm}$ in the first measurement period, and $124(\mathrm{SD} 20.3 ; \mathrm{n}=5) \mathrm{mm}$, corresponding to 958 (SD 260.3) $\mathrm{kg}$ of DM/ha for the second measurement period. The average postgrazing sward surface height was $56(\mathrm{SD} 3.1 ; \mathrm{n}=10) \mathrm{mm}$ in the first measurement period and $64(\mathrm{SD} 10.1 ; \mathrm{n}=5)$ $\mathrm{mm}$ in the second measurement period. Herbage mass above $50 \mathrm{~mm}$ ( $\mathrm{kg}$ of $\mathrm{DM} / \mathrm{ha}$ ) was calculated according to $-625+12.8 \times$ sward height $(\mathrm{mm})$. This regression was calibrated on the same paddocks during the vegetation period $1 \mathrm{yr}$ before the current study $\left(\mathrm{R}^{2}=\right.$ $0.84, \mathrm{n}=89)$. The pastures were long established and composed predominantly of grasses (mainly Lolium perenne, Dactylis glomerata, and Phleum pratense) but also of clover (mainly Trifolium repens) and forbs (mainly Taraxacum officinale). The pastures were fertilized once per year with $25 \mathrm{~m}^{3} /$ ha of farm-produced manure (corresponding to approximately $80 \mathrm{~kg}$ of N, 22 $\mathrm{kg}$ of $\mathrm{P}$, and $108 \mathrm{~kg}$ of $\mathrm{K}$ per ha). The ambient outdoor temperature and rainfall were recorded daily by the meteorological station in Grangeneuve (Meteo-Schweiz, Station Grangeneuve, Switzerland), located about 15 $\mathrm{km}$ north of the experimental pastures. During the first measurement period, the average temperature was $12^{\circ} \mathrm{C}$ (minimum $6^{\circ} \mathrm{C}$, maximum $17^{\circ} \mathrm{C}$ ) and in the second measurement period $19^{\circ} \mathrm{C}$ (minimum $16^{\circ} \mathrm{C}$, maximum $20^{\circ} \mathrm{C}$ ). On 7 out of the $14 \mathrm{~d}$, scattered rain showers occurred with an average daily precipitation of 7 (SD 10.1) $\mathrm{mm}$ in the first measurement period, whereas on 2 out of the $14 \mathrm{~d}$ in the second measurement period the average daily precipitation was $1 \mathrm{~mm}$.

\section{Concentrate Supplementation}

Figure 1 shows the description of the experiment setup. A step-wise adaptation to the targeted amount of concentrate, 0 or $6 \mathrm{~kg}$ (as-fed basis), took place during 
the first $14 \mathrm{~d}$ of the adaptation periods of $21 \mathrm{~d}$ before data collection periods. Six days before the data collection periods and during the whole data collection periods, the organic, commercial concentrate mix (UFA 275 Bio, UFA AG, Herzogenbuchsee, Switzerland; composition in descending order according to the delivery note: corn, wheat bran, wheat, barley, sorghum mill feed, barley mill feed, rye, sugar-beet molasses, oats, vegetable oil, minerals, and sunflower seed press cake), was mixed with $10 \%$ of labeled barley $(50 \mathrm{~g} / \mathrm{kg}$ of octacosane HC28, $\mathrm{C}_{28} \mathrm{H}_{58}$, Acros Organics BVBA, Geel, Belgium). The concentrate was fed after milking in 2 equal meals $(3 \mathrm{~kg}$ at $0600 \mathrm{~h}$ and $3 \mathrm{~kg}$ at $1700 \mathrm{~h}$ ) at the feed fence in the freestall barn using separate buckets for each cow. During the data collection periods, all 6 $\mathrm{kg} / \mathrm{d}$ of concentrate was ingested by all cows with no refusals. The nonsupplemented cows received no concentrate in addition to pasture. Fresh water was always available and a mineral block was available in the barn.

\section{Data Recording and Sample Collection}

Individual feed intake was estimated with the $n$-alkane double indicator technique (Mayes et al., 1986). Gelatin capsules (HGK 17-60 sl; Capsula GmbH, Ratingen, Germany), containing $0.5 \mathrm{~g}$ (weighing accuracy 0.01) dotriacontane (HC32, $\mathrm{C}_{32} \mathrm{H}_{66}$, Argenta Ltd., Auckland, New Zealand) on a carrier of dried fruit pomace and $1.0 \mathrm{~g}$ of ytterbium(III) oxide (purity: 99.99\%, REacton, Alfa Aesar GmbH \& Co KG, Karlsruhe, Germany), were administered twice per day starting $6 \mathrm{~d}$ before the data collecting periods. The ytterbium(III) oxide was added to calculate relative FR of alkanes, LCFA, and LCOH. During the data collection periods, a daily spot sample of feces was taken from each cow with or without stimulus between 0700 and $0800 \mathrm{~h}$. Samples were pooled by cow and data collection period and stored at $-20^{\circ} \mathrm{C}$. For estimating feed intake, herbage samples were collected starting $1 \mathrm{~d}$ before the feces sampling. Herbage sample collection was carried out every morning and evening as described by Graf et al. (2005). Samples were chopped and stored at $-20^{\circ} \mathrm{C}$ until further analysis. Samples of commercial concentrate mix and labeled barley were taken daily, pooled per data collection period and analyzed separately.

Milk yield (Flo Master Pro, DeLaval AG, Sursee, Switzerland) was recorded daily and milk composition was analyzed from a pooled sample of aliquot proportion of morning and evening milk on d 1, 4, and 7 of each data collection period. Milk samples were preserved in tubes containing Broad-Spectrum Microtabs II (Gerber Instruments AG, Effretikon, Switzerland) at $8^{\circ} \mathrm{C}$. Grazing and rumination behavior was recorded automatically using jaw movement recorders (Datenlogger MSR
145, MSR Electronics GmbH, Hengart, Switzerland), and for recording physical activity IceTag pedometers (IceRobotics Ltd., Edinburgh, UK) were used. Further details are described by Thanner et al. (2014).

During the data collection periods, 2 per measurement period, 2 strips of herbage per paddock were cut before the cows entered the new paddock for estimation of the botanical composition and to collect plant species or groups for the marker analysis. In the first data collection period, cows grazed on 10 different paddocks and in the second period cows grazed on 5 different paddocks. The strips, 7 to $9 \mathrm{~m}$ long and $1 \mathrm{~m}$ wide, were cut with a motor mower Rapid BM 117 (Rapid Technic AG, Killwangen, Switzerland). The harvested biomass was collected in plastic bags and subsamples were manually separated for botanical analysis. Dominant plant species were Lolium perenne, D. glomerata, T. repens, and Taraxacum officinale. Other grass species were merged as "other grass" representing Phleum pratense, Poa pratensis, Poa annua, Festuca pratensis, Agrostis spp., and Holcus lanatus. Further forbs were merged as "other forbs" representing Plantago lanceolata, Ranunculus acris, and Rumex acetosa. Plant species or group samples of every data collection period, 4 in total, were collected, weighed, and chemically analyzed. The average proportion of the plant species or groups over all subsamples of all data collection periods was $27.8 \% \mathrm{~L}$. perenne, $6.1 \%$ D. glomerata, $38.2 \%$ other grass, $10.4 \%$ T. repens, $9.0 \%$ T. officinale, and $8.5 \%$ other forbs.

\section{Extraction and Analysis of Alkanes, LCFA, and LCOH}

Samples of plant species, concentrate, and feces were analyzed for the concentrations of alkanes, LCFA and $\mathrm{LCOH}$ according to the methods of Dove and Mayes (2006) without the steps for further purification of LCFA and LCOH fractions. Samples of alkanes, $\mathrm{LCOH}$, and LCFA were dissolved in dodecane before analysis by gas chromatography, using a Trace 1300 GC fitted with an AS 1300 series autosampler and a flame ionization detector (Thermo Scientific, Hemel Hempstead, UK) equipped with a nonpolar-fused silica capillary column (CPSil-5CB, $50 \mathrm{~m} \times 0.32 \mathrm{~mm} \times 0.12$ $\mathrm{mm}$, Agilent Technologies, Santa Clara, CA). The temperature program used for alkanes and LCFA was initial oven temperature $170^{\circ} \mathrm{C}$, hold for $4 \mathrm{~min}$; first gradual increase $30^{\circ} \mathrm{C} / \mathrm{min}$ to $215^{\circ} \mathrm{C}, 1 \mathrm{~min}$ hold; second gradual increase $6^{\circ} \mathrm{C} / \mathrm{min}$ to $300^{\circ} \mathrm{C}, 10 \mathrm{~min}$ hold. The temperature program used for $\mathrm{LCOH}$ was initial oven temperature $40^{\circ} \mathrm{C}$, first gradual increase $20^{\circ} \mathrm{C} / \mathrm{min}$ to $130^{\circ} \mathrm{C}$; second gradual increase $4^{\circ} \mathrm{C} / \mathrm{min}$ to $250^{\circ} \mathrm{C}$; third gradual increase $1.5^{\circ} \mathrm{C} / \mathrm{min}$ to $300^{\circ} \mathrm{C}$, hold for $10 \mathrm{~min}$. Mixed standard solutions were run regularly to enable corrections for variation in detector response. To allow 
peak identification several samples of the diet components and feces were also analyzed using GC described above, equipped with an identical column, coupled to an ISQ mass spectrometer (Thermo Scientific). The ion source was maintained at $300^{\circ} \mathrm{C}$ and the transfer line at $300^{\circ} \mathrm{C}$. The emission current was set to $50 \mathrm{~mA}$ and the electron energy to $70 \mathrm{eV}$. The analyzer was set to scan at 50 to $650 \mathrm{~m} / z$ with a scan cycle time of $0.6 \mathrm{~s}$.

The alkanes with a carbon chain length (CCL) of 24 to 33 were analyzed. The LCFA with the even number CCL of 22 to 34 and the LCOH with the even number CCL of 20 to 30 were analyzed, as they occur in higher concentrations compared with odd chain substances.

\section{Further Laboratory Analysis}

Milk samples were analyzed by infrared spectrometry (Combifoss FT+, Foss, Hillerød, Denmark) for contents of fat, protein, and lactose (International Dairy Federation, 2000; method number 141C). Urea in milk was determined with a differential $\mathrm{pH}$-analyzer (Eurochem, Ardea, Italy) before and after hydrolysis with urease (International Dairy Federation, 2004; method number 195). For milk acetone determination, acetone and an internal standard (2-butanone) were transferred via static headspace directly from the milk into the gas phase. The composition of the gas phase was determined with a flame ionization detector on a GC (HP 5890 Series II, Agilent Technologies, Santa Clara, CA).

Herbage, plant species, and feces samples were lyophilized (model Delta, 1-24 LSC, Christ, Osterode, Germany). Thereafter, concentrate, herbage, plant species, and feces samples were milled through a $1.0-\mathrm{mm}$ screen (Brabender mill with titanium blades, Brabender, Duisburg, Germany). Subsamples of the lyophilized samples were dried for $3 \mathrm{~h}$ at $105^{\circ} \mathrm{C}$ to determine $\mathrm{DM}$ and subsequently incinerated at $550^{\circ} \mathrm{C}$ until they reached a stable mass to assess the ash contents. The contents of alkanes HC32 and tritriacontane (HC33, $\left.\mathrm{C}_{33} \mathrm{H}_{68}\right)$ were determined as described by Peiretti et al. (2006). The $\mathrm{N}$ content was determined using the Dumas method (AOAC International, 1995) on a $\mathrm{C} / \mathrm{N}$ analyzer (type FP-2000, Leco Instruments, St. Joseph, $\mathrm{MI})$ and then multiplied by 6.25 to determine the $\mathrm{CP}$ content. The ether extract was determined using the Soxtec Avanti 2050 apparatus for extraction following the guidelines of VDLUFA (2012, method 5.1.1.). Acid detergent fiber (procedure 973.18; AOAC International, 1995) was determined with correction for residual ash obtained after incineration at $500^{\circ} \mathrm{C}$ for $1 \mathrm{~h}$. For analyzing $\mathrm{Yb}$, subsamples were dissolved in $\mathrm{HNO}_{3}$ before analyzed with an inductively coupled plasma optical emission spectrometry (ICP-OES Optima 2000 DV, Perkin Elmer, Shelton, CT, with system ICP-OES Op- tima 7300). Crude fiber was analyzed only in herbage, plant species, and concentrate samples according to the procedure 978.10 (AOAC International, 1995) and NDF (Mertens, 2002) was assessed with the addition of heat-stable amylase and sodium sulfite. Starch content was determined based on the polarimetric method (ISO, 2000; method 6493) in concentrate samples. Water-soluble carbohydrates (WSC) and ethanol-soluble carbohydrates (ESC) were analyzed according to Hall et al. (1999) and determined with the Thermo Scientific Genesys 10S Vis Spectrophotometer (Thermo Scientific, Waltham, MA). Lignin was analyzed according to the procedure 973.18 (AOAC International, 1995).

\section{Calculation of Fecal Recovery and Estimation of Diet Composition}

The correction for incomplete FR was performed in 2 different ways. To estimate average marker concentration in the herbage $\left(\mathbf{H}_{\mathrm{M}}\right)$ for the subsequent calculation of individual FR of each marker substance $\left(\mathbf{F R}_{\mathrm{M}}\right)$, the average botanical composition of the pasture was assessed in 2 different ways.

Method 1: With the alkane concentrations of the representative herbage samples and from the plant species, the average botanical composition for each data collection week was calculated using a nonnegative leastsquares procedure in R (R Core Team, 2012). Mean $\mathrm{FR}$ rates were subsequently calculated with the formula described below for alkanes, LCOH, and LCFA across all data collection weeks (FR1).

Method 2: The manually assessed botanical composition was used to calculate $\mathrm{H}_{\mathrm{M}}$ (FR2). The relative FR of alkanes (CCL: 24-33), LCFA (CCL: 22, 24, 26, 28, 30, 32, and 34), and LCOH (CCL: 20, 22, 24, 26, 28 , and 30$)$ to $\mathrm{Yb}$ were calculated with the following equation:

$$
\begin{gathered}
\mathrm{FR}_{\mathrm{M}}=\left(\mathrm{D}_{\mathrm{Yb}}+\mathrm{DMI}_{\mathrm{H}} \times \mathrm{H}_{\mathrm{Yb}}\right) \times \mathrm{FR}_{\mathrm{Yb}} \times \mathrm{F}_{\mathrm{M}} / \\
{\left[\left(\mathrm{D}_{\mathrm{HC} 32}+\mathrm{DMI}_{\mathrm{H}} \times \mathrm{H}_{\mathrm{M}}+\mathrm{DMI}_{\mathrm{Conc}} \times \mathrm{Conc}_{\mathrm{M}}\right) \times \mathrm{F}_{\mathrm{Yb}}\right],}
\end{gathered}
$$

where $\mathrm{D}$ is the dosed amount of $\mathrm{Yb}\left(\mathrm{D}_{\mathrm{Yb}}\right)$ and $\mathrm{HC} 32$ ( $\mathrm{D}_{\mathrm{HC} 32}$; just used for FR calculation of $\left.\mathrm{HC} 32\right), \mathrm{H}$ is the concentration of $\mathrm{Yb}\left(\mathrm{H}_{\mathrm{Yb}}\right)$ in herbage, $\mathrm{FR}_{\mathrm{Yb}}$ is the $\mathrm{FR}$ of $\mathrm{Yb}$ fixed to $0.95, \mathrm{~F}$ is the concentration of $\mathrm{Yb}\left(\mathrm{F}_{\mathrm{Yb}}\right)$ and marker $\left(\mathrm{F}_{\mathrm{M}}\right)$ in feces, and $\mathrm{Conc}_{\mathrm{M}}$ is the concentration of markers in the concentrate (only included for supplemented cows). Total DMI was separated into herbage DMI $\left(\mathrm{DMI}_{\mathrm{H}}\right)$ and concentrate $\mathrm{DMI}\left(\mathrm{DMI}_{\mathrm{Conc}}\right)$.

With the average $\mathrm{FR}_{\mathrm{M}}$ of all cows over both measurement periods, concentrations of alkanes, $\mathrm{LCOH}$, and LCFA in feces were corrected for the diet composition estimation. 
Diet composition of each animal was estimated using a nonnegative least-squares procedure included in the software "EatWhat" (Dove and Moore, 1995). Estimations were performed with alkanes, LCFA, and $\mathrm{LCOH}$ alone, and their combination. Furthermore, all diet composition estimations were performed with data not corrected for FR, with FR1, and FR2 resulting in 21 combinations (7 marker and marker combinations and 3 FR). For supplemented cows, concentrate was included as a diet component. The alkanes administered with the capsules were considered in diet estimations with alkanes or in marker combination with alkanes.

\section{Other Calculations and Statistical Analyses}

The $\mathrm{NE}_{\mathrm{L}}$ and the absorbable protein in the small intestine when rumen fermentable energy is limiting microbial protein synthesis in the rumen were calculated according to Agroscope (2013). The ECM was calculated based on a $4 \%$ fat, $3.2 \%$ protein, and $4.8 \%$ lactose basis (Agroscope, 2013). Feed intake was estimated with the equation proposed by Mayes et al. (1986) using the alkanes HC32 and HC33. The statistical analyses for milk yield and composition, rumination and grazing behavior, physical activity, and feed intake were carried out with SYSTAT 13 (Systat Software Inc., Chicago, IL). The data were collected over several days and averaged per cow, day, and measurement period. The averages were analyzed using the following linear mixed model:

$$
\begin{gathered}
\mathrm{Y}_{\mathrm{ijklm}}=\mu+\tau_{\mathrm{i}}+\varphi_{\mathrm{j}}+\mathrm{p}_{\mathrm{k}}+(\tau \mathrm{p})_{\mathrm{ik}}+(\tau \varphi)_{\mathrm{ij}} \\
+\mathrm{P}_{1}+\mathrm{K}_{\mathrm{m}}\left(\mathrm{P}_{1}\right)+\varepsilon_{\mathrm{ijk} \mathrm{m}},
\end{gathered}
$$

where $Y_{\mathrm{ijklm}}$ is the response (respectively, its logarithm), $\mu$ is the least squares means, $\tau_{i}$ is the fixed effect of cow strain i $(\mathrm{i}=\mathrm{HCH}, \mathrm{HNZ}), \varphi_{\mathrm{j}}$ is the fixed effect of the treatment $\mathrm{j}(\mathrm{j}=$ nonsupplemented, supplemented cows $), p_{k}$ is the fixed effect of the period $(k=$ period 1 , period 2), $(\tau p)_{\text {ik }}$ is the effect of the interaction between cow strain $\mathrm{i}$ and period $\mathrm{k},(\tau \varphi)_{\mathrm{ij}}$ is the effect of the interaction between cow strain $i$ and treatment $j, P_{1}$ is the random effect of cow pair $l(1, \ldots, 12), \mathrm{K}_{\mathrm{m}}$ is the random effect of the cow $\mathrm{m}(1, \ldots, 24)$, and $\varepsilon_{\mathrm{ijklm}}$ is the random error. The effects were considered significant at $P \leq 0.05$. A value of $0.05<P<0.10$ was considered a trend.

Linear discriminant analyses were performed with SYSTAT 13 for evaluating the differentiation of marker profiles of the plant species and the concentrate. Results are summarized in a jackknifed classification matrix where the percentage of correct allocations of marker profiles to the plant species is presented. The concen- trate percentage of the diet of supplemented cows was subtracted from the results of entire diet estimated with "EatWhat" and compared with the manually assessed botanical composition. Based on the Aitchison distance measure (Aitchison et al., 2000) the similarity between botanical compositions and diet estimations was tested with the R package "compositions" to figure out the marker group and FR with the most accurate diet estimation. Using the R package PCS (Wilson, 2013), the marker group combinations with the most accurate diet estimation were determined. A parametric linear mixed model was applied to the Aitchison distances of the 2 best marker and FR combinations to test whether they differ significantly from each other (SYSTAT 13). The most accurate marker group combination for diet estimation was selected and the effects of concentrate supplementation and of cow strain were tested with the R package "composition" as described in van den Boogaart et al. (2014). Zeroes in the estimated compositions were first replaced by the nonparametric imputation procedure proposed by Martín-Fernández et al. (2003). For each plant variety, a robust linear mixed model (Koller, 2015) was applied to the logarithms of the estimated compositional results of the most accurate diet estimation to test the effects of concentrate supplementation and of cow strain.

\section{RESULTS}

\section{Chemical Composition of Herbage and Concentrate}

In Table 1, the average chemical composition of the herbage samples from the paddocks for each measurement period is presented. All analyzed components are similar in both measurement periods. The average chemical composition of plant species and concentrate is displayed in Table 2. Small differences were recorded between plant species; for example, T. repens had the highest concentration of $\mathrm{CP}$, but the lowest concentration of WSC. Grass species, including L. perenne, D. glomerata, and the group of other grass, had a higher concentration of crude fiber, ADF, and NDF than the other plant species. As the concentrate was a commercial mix based on grain, the chemical composition was similar to the labeled barley with high $\mathrm{NE}_{\mathrm{L}}$ concentration $(8.0 \mathrm{MJ} / \mathrm{kg}$ of $\mathrm{DM}$ for both) and medium $\mathrm{CP}$ concentration (127 and $138 \mathrm{~g} / \mathrm{kg}$ of DM, respectively).

\section{Milk Yield, Milk Composition, and DMI}

Nonsupplemented cows had lower $(P<0.001)$ milk production compared with supplemented cows (Table 3). Swiss Holstein cows had higher milk yield, but no difference between cow strains was recorded for 
additional milk yield per kilogram of concentrate. Concentrate supplementation had no effect on ECM yield and no difference between cow strains occurred. Nonsupplemented cows had a higher $(P<0.001)$ milk fat content and a lower $(P<0.01)$ milk protein content. Swiss Holstein cows had a lower $(P<0.05)$ milk fat and a lower $(P<0.001)$ milk protein content compared with HNZ cows. Concentration of acetone and urea in milk were influenced by concentrate supplementation with greater $(P<0.001)$ concentrations for nonsupplemented cows. Nonsupplemented cows had a higher $(P$ $<0.001$ ) herbage DMI compared with supplemented cows, but total DMI was lower $(P<0.001)$ for nonsupplemented cows. No further difference between cow strains and no interactions for aforementioned traits were observed.

\section{Grazing and Rumination Behavior and Physical Activity}

Grazing time, grazing mastication, and grazing mastication rate were higher $(P<0.001)$ for nonsupplemented cows, but no differences between cow strains were recorded (Table 4). Concentrate supplementation had no influence on rumination behavior, but nonsupplemented cows tended to have a lower number of mastications per bolus than supplemented cows $(P=$ $0.08)$. Swiss Holstein cows spent slightly $(P=0.09)$ less time ruminating and made less rumination masti- cations. A trend $(P=0.06)$ for a lower number of boli per day was recorded for $\mathrm{HCH}$ cows compared with HNZ cows. Physical activity was not influenced by concentrate supplementation. No difference between cow strains was recorded for time spent lying or standing. The HCH cows had a tendency to walk less $(P=0.07)$ and made fewer $(P=0.03)$ steps compared with HNZ cows. No interactions were recorded.

\section{Composition of Diet Components, Fecal Recovery, and Diet Selection}

Concentration of alkanes, LCFA, and LCOH of plant species and concentrate are given in Table 5 . The LCOH had the highest average concentration with $446 \mathrm{mg} / \mathrm{kg}$ of DM compared with alkanes $(21 \mathrm{mg} /$ $\mathrm{kg}$ of DM) and LCFA (277 mg/ $\mathrm{kg}$ of DM). The oddchain alkanes were in higher concentration compared with even-chain numbered alkanes. For $L$. perenne, D. glomerata, other grass, and other forbs the $\mathrm{C}_{31} n$-alkane had the highest concentration, but for T. repens and $T$. officinale the $\mathrm{C}_{29} n$-alkane was most abundant. Alkane concentration in concentrate was generally low $(<3$ $\mathrm{mg} / \mathrm{kg}$ of DM) except for the $\mathrm{C}_{28} n$-alkane from labeled barley added to the concentrate. The $\mathrm{C}_{24} n$-alkane had the lowest concentration of those measured with $<1$ $\mathrm{mg} / \mathrm{kg}$ of $\mathrm{DM}$ in all diet components. In general, the highest overall average alkane concentration in plant species was analyzed for L. perenne with $36 \mathrm{mg} / \mathrm{kg}$ of

Table 1. Average chemical composition of herbage samples $(n=28$; mean $\pm \mathrm{SD})$

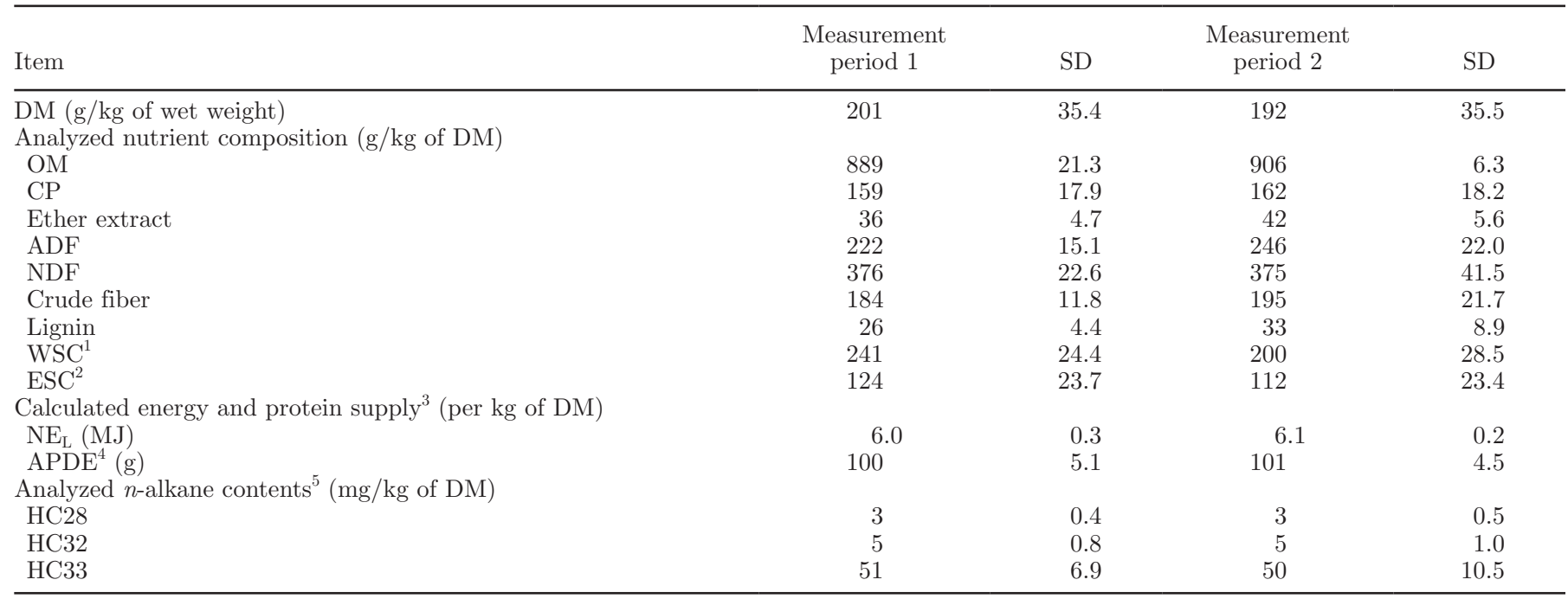

${ }^{1} \mathrm{WSC}=$ water-soluble carbohydrates.

${ }^{2} \mathrm{ESC}=$ ethanol-soluble carbohydrates.

${ }^{3}$ According to Agroscope (2013).

${ }^{4} \mathrm{APDE}=$ absorbable protein in the small intestine when rumen fermentable energy is limiting microbial protein synthesis in the rumen.

${ }^{5} \mathrm{HC} 28=$ octacosane, $\mathrm{C}_{28} \mathrm{H}_{58} ; \mathrm{HC} 32=$ dotriacontane, $\mathrm{C}_{32} \mathrm{H}_{66} ; \mathrm{HC} 33$ = tritriacontane, $\mathrm{C}_{33} \mathrm{H}_{68}$. 
HEUBLEIN ET AL.

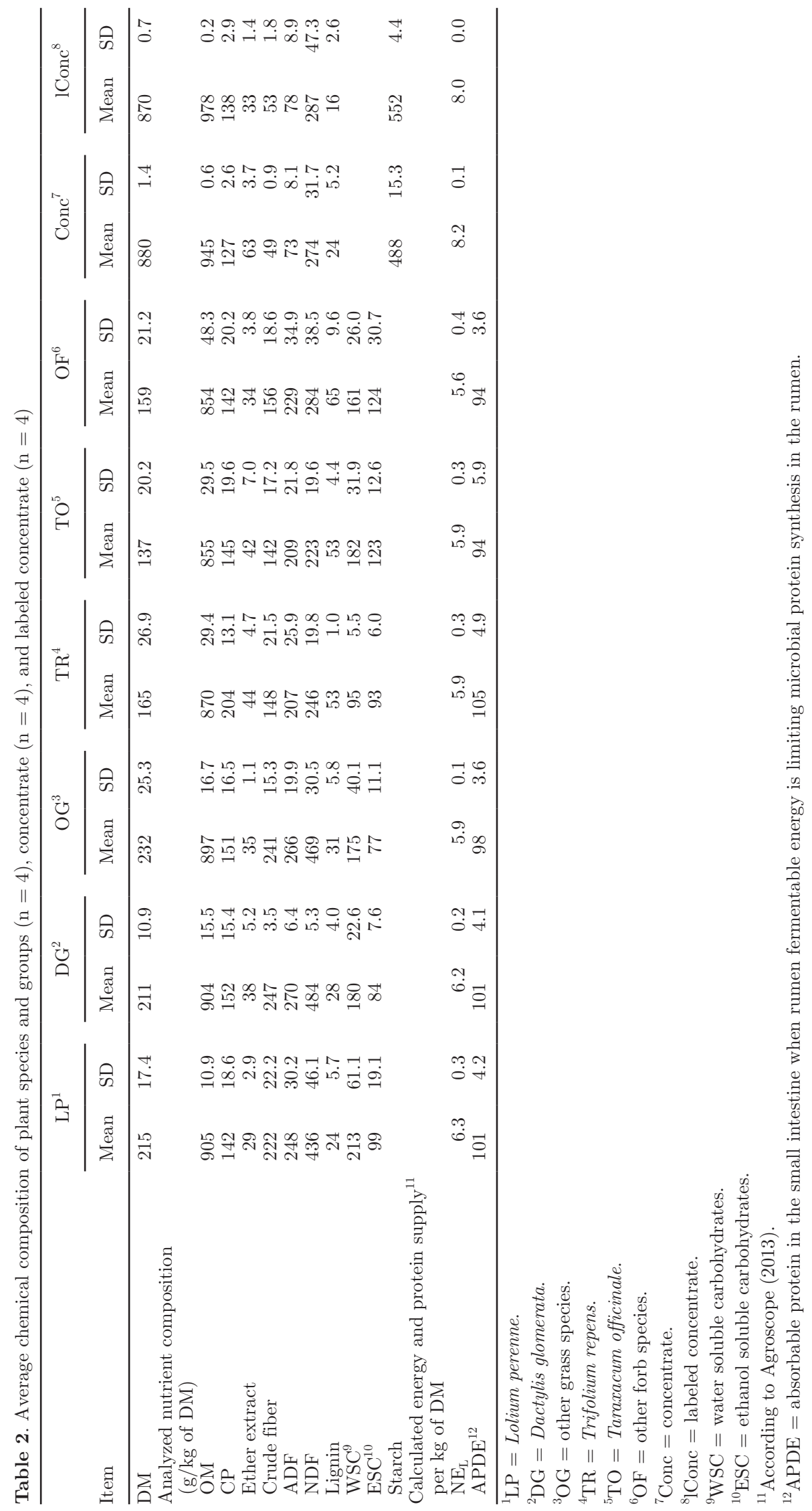


Table 3. Effect of concentrate supplementation ${ }^{1}$ and cow strain ${ }^{2}$ on milk production performance and feed intake

\begin{tabular}{|c|c|c|c|c|c|c|c|c|}
\hline Item & \multicolumn{2}{|c|}{ Conc0 } & \multicolumn{2}{|c|}{ Conc6 } & SD & \multicolumn{3}{|c|}{$P$-value } \\
\hline Milk yield ( $\mathrm{kg} / \mathrm{kg}$ of concentrate) & & & 0.49 & 0.40 & 0.44 & 0.55 & & \\
\hline $\operatorname{ECM}(\mathrm{kg} / \mathrm{d})$ & 21.7 & 20.9 & 22.6 & 21.6 & 4.05 & 0.44 & 0.18 & 0.86 \\
\hline Fat $(\%)$ & 3.7 & 4.0 & 3.0 & 3.3 & 0.45 & 0.03 & $<0.001$ & 0.92 \\
\hline Acetone $(\mathrm{mg} / \mathrm{L})$ & 2.7 & 2.3 & 1.6 & 1.5 & 0.64 & 0.26 & $<0.001$ & 0.35 \\
\hline Urea $(\mathrm{mg} / \mathrm{L})$ & 248 & 245 & 222 & 210 & 30.7 & 0.48 & $<0.001$ & 0.55 \\
\hline \multicolumn{9}{|l|}{ Feed intake } \\
\hline Herbage DMI (kg/d) & 15.4 & 14.7 & 12.2 & 10.9 & 2.30 & 0.10 & $<0.001$ & 0.28 \\
\hline Total DMI $(\mathrm{kg} / \mathrm{d})$ & 15.4 & 14.7 & 17.4 & 16.1 & 2.30 & 0.10 & $<0.001$ & 0.28 \\
\hline
\end{tabular}

${ }^{1}$ Conc0 = nonsupplemented cows; Conc6 = cows supplemented with $6 \mathrm{~kg} / \mathrm{d}$ of concentrate.

${ }^{2} \mathrm{HCH}=$ Swiss Holstein-Friesian cows; HNZ = New Zealand Holstein-Friesian cows.

DM and the lowest for $T$. officinale with $10 \mathrm{mg} / \mathrm{kg}$ of DM. The highest concentrations of LCFA occurred for those with CCL of $22,24,26$, and 28, and the lowest concentration was recorded for the $\mathrm{C}_{34}$ LCFA in all diet components. The highest average LCFA concentration in plant species occurred for T. repens with $426 \mathrm{mg} / \mathrm{kg}$ of DM and the lowest for L. perenne with $163 \mathrm{mg} / \mathrm{kg}$ of DM. The $\mathrm{C}_{26} \mathrm{LCOH}$ had the highest concentration and the $\mathrm{C}_{20} \mathrm{LCOH}$ had the lowest concentration in all diet components, except for $T$. repens, where the $\mathrm{C}_{30}$ $\mathrm{LCOH}$ had the highest and the $\mathrm{C}_{20}$ and $\mathrm{C}_{22} \mathrm{LCOH}$ had the lowest concentration. Dactylis glomerata had the highest average LCOH concentrations in plant species with $1,150 \mathrm{mg} / \mathrm{kg}$ of DM and $T$. repens had the lowest with $257 \mathrm{mg} / \mathrm{kg}$ of DM.
Most accurate discrimination of diet composition was achieved with the $\mathrm{LCOH}$, where $96 \%$ of the plant species or groups were correctly allocated (Table 6). A score of $81 \%$ correct allocations was obtained with alkanes or LCFA. The marker combination with the most accurate allocation (81\%) was LCFA and LCOH. Finally, the weakest discrimination with $12 \%$ correct allocation resulted from the combination of all 3 marker groups. The most accurate diet component allocation was achieved for concentrate, where a $100 \%$ allocation was accomplished unless all 3 marker groups were used. The plant-specific correct allocation varied from 50 to $77 \%$ with the best allocation for T. repens $(77 \%)$ followed by $D$. glomerata $(71 \%)$. The least accurate average allocation was achieved for $L$. perenne as it was

Table 4. Effect of concentrate supplementation ${ }^{1}$ and cow strain ${ }^{2}$ on grazing and rumination behavior as well as on physical activity over $24 \mathrm{~h}$

\begin{tabular}{|c|c|c|c|c|c|c|c|c|}
\hline Item & \multicolumn{2}{|c|}{ Conc0 } & \multicolumn{2}{|c|}{ Conc6 } & SD & \multicolumn{3}{|c|}{$P$-value } \\
\hline \multicolumn{9}{|l|}{ Grazing behavior over $24 \mathrm{~h}$} \\
\hline Mastications (no.) & 40,066 & 42,130 & 33,279 & 34,166 & 4,418 & 0.17 & $<0.001$ & 0.58 \\
\hline Mastication rate (no./min) & 73.8 & 75.4 & 71.6 & 72.7 & 3.58 & 0.30 & $<0.01$ & 0.83 \\
\hline \multicolumn{9}{|l|}{ Rumination behavior over $24 \mathrm{~h}$} \\
\hline Mastication rate (no./min) & 72.8 & 73.9 & 71.7 & 74.3 & 4.67 & 0.31 & 0.67 & 0.34 \\
\hline Rumination boli (no.) & 533 & 610 & 532 & 584 & 80.4 & 0.06 & 0.20 & 0.23 \\
\hline Mastications boli (no./boli) & 56.3 & 52.8 & 57.3 & 58.4 & 9.79 & 0.76 & 0.08 & 0.20 \\
\hline \multicolumn{9}{|l|}{ Activity over $24 \mathrm{~h}$} \\
\hline Lying (min) & 473 & 465 & 521 & 478 & 75.3 & 0.22 & 0.16 & 0.40 \\
\hline Standing and moving (min) & 968 & 976 & 920 & 963 & 75.3 & 0.22 & 0.16 & 0.40 \\
\hline Walking (min) & 355 & 422 & 353 & 390 & 93.0 & 0.07 & 0.55 & 0.59 \\
\hline
\end{tabular}

${ }^{1}$ Conc0 $=$ nonsupplemented cows; Conc6 = supplemented cows.

${ }^{2} \mathrm{HCH}=$ Swiss Holstein-Friesian cows; HNZ = New Zealand Holstein-Friesian cows. 
HEUBLEIN ET AL.

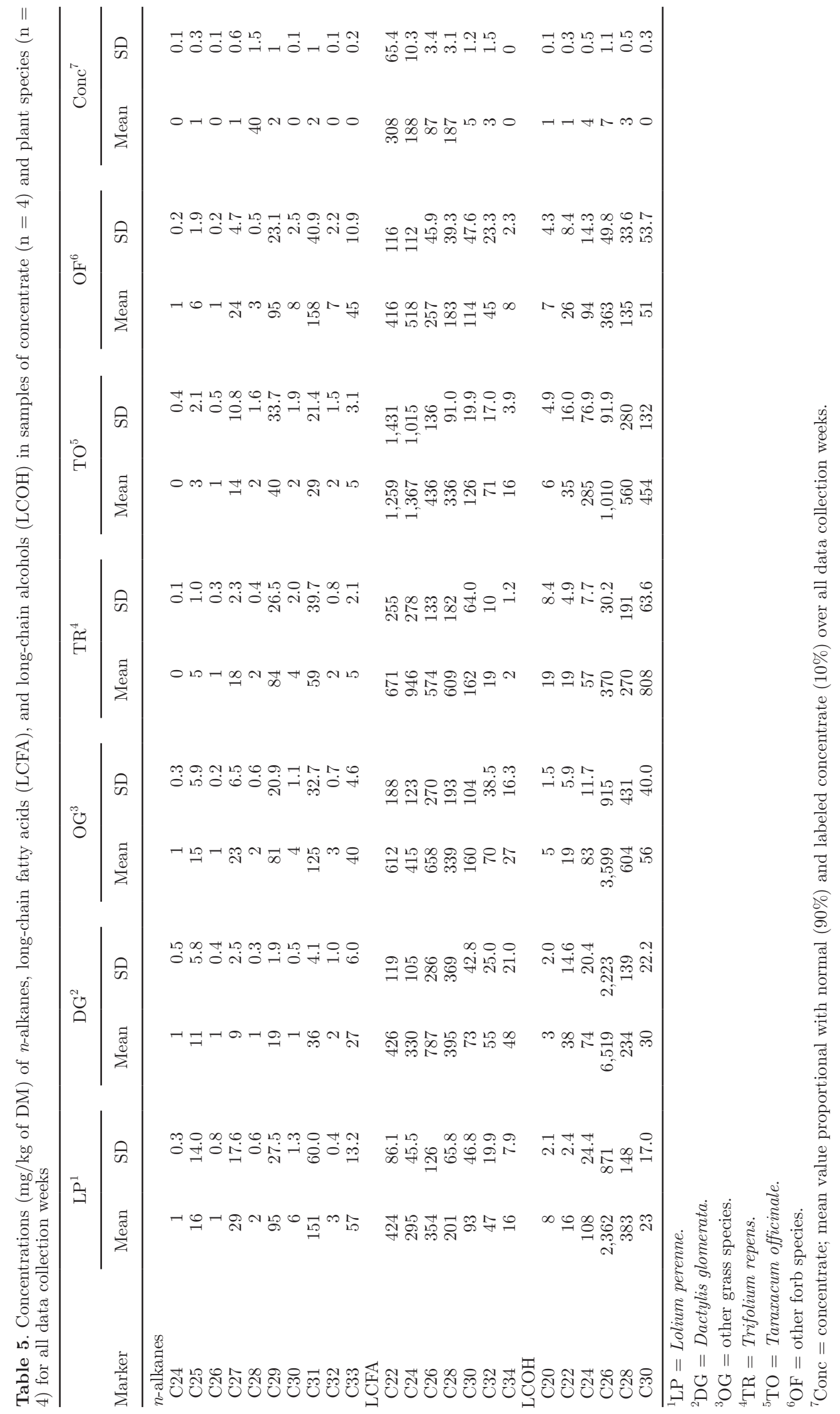


frequently mixed up with the group of other grass (data not shown). In Figure 2, the results of calculated FR are presented for alkanes, LCFA, and LCOH. All FR increased with increasing CCL, except for the FR2 of the $\mathrm{LCOH}$, where FR increased until $\mathrm{LCOH}$ with a CCL of 26 and decreased for the ones with a CCL of 28 and 30. Both FR methods for alkanes and $\mathrm{LCOH}$ indicated an incomplete recovery $(\mathrm{FR}<1.0)$ of the lower CCL alkanes $\left(\mathrm{C}_{24}\right.$ to $\left.\mathrm{C}_{32}\right)$ and $\mathrm{LCOH}\left(\mathrm{C}_{20}\right.$ to $\left.\mathrm{C}_{28}\right)$, but were $>1.0$ for the $\mathrm{C}_{33}$ alkane and the $\mathrm{C}_{30} \mathrm{LCOH}$. The average FR of LCFA was higher than the FR of alkanes and LCOH. For the LCFA with a CCL of 26 to $32 \mathrm{FR}$ was $>1.0$ with the highest rate for the LCFA with a CCL of $26(\mathrm{FR} 1=2.6$, and FR2 $=2.4)$.

The accuracy of the diet composition estimation depending on the marker combinations was ranked based on the Aitchison distance (Table 7). With the combination alkanes, $\mathrm{LCOH}$ and FR1, the most accurate estimation was achieved (smallest Aitchison distance), as shown in Figure 3, with and without concentrate included, compared with the assessed botanical composition. The least accurate diet composition estimations were achieved with the combination alkanes and LCFA, and LCFA alone: with or without FR correction. Using the most accurate marker group combination, alkanes, $\mathrm{LCOH}$, and FR1, differences between cow strains or concentrate supplementation on diet composition has been tested (Table 8). Results indicate no difference between cow strains $(P=0.49)$, but an effect of concentrate supplementation $(P=0.02)$ on diet selection. Nonsupplemented cows had a lower $(P<0.05)$ proportion of $T$. repens in their diet compared with supplemented cows.

\section{DISCUSSION}

\section{Plant Wax Concentration and Profiles of Plant Species}

A sufficient differentiation between plant species is essential for successful diet estimation. Differentiation between plant species with alkanes, LCFA, and LCOH is feasible, but most previous studies included only a few pasture plant species (Boland et al., 2012) or studied diets containing herbaceous and heathland woody species (Ferreira et al., 2009). Similar marker profiles between different species result in incorrect allocations, which create a challenge for accurate diet composition estimation. Therefore, plant species from the same genus or plants with similar marker profile can be summarized and denoted as one diet component (Ferreira et al., 2011). However, differences in palatability and consequently intake have to be considered. For example, D. glomerata is less preferred than L. perenne when taking the whole grazing season into account (Ivins, 1952), because the decline in quality of $D$. glomerata is more rapid than that of $L$. perenne. Concentrations of all 3 marker groups varied within plant species samples, which was attributed to environmental conditions (Dove et al., 1996) and simultaneous sampling of plant species and animal feces is required. Date of sampling influences the alkanes concentration depending on the plant growth stage, as concentration differs between plant parts. The highest is in the florescence, at least for L. perenne (Dove et al., 1996; Ferreira et al., 2009), T. officinale, and T. repens (Gedir and Hudson, 2000). Ferreira et al. (2009, 2015) observed similar LCFA and $\mathrm{LCOH}$ marker profiles of $L$. perenne for leaf and stem fractions, and for the spike fraction, and there may be only minor differences between plant parts in other plant species, which should be tested in future studies. The concentration of the $\mathrm{C}_{31}$ alkane was high in samples of $L$. perenne and in the group of other grass, which is typical for grass species (Bush and McInerney, 2013). Furthermore, alkane and LCFA profiles of $L$. perenne and other grass were similar, probably because cognate grasses such as Lolium multiflorum are included in the group of other grass, resulting in frequent mixing up in the outcome of the linear discriminant analysis. The $\mathrm{C}_{29}$ alkane was dominant in T. repens, which is typical for legumes (Dove et al., 1996; Charmley and Dove, 2007), and a $100 \%$ correct assignment of $T$. repens profiles was achieved with alkanes. In accordance with Schori et al. (2012), T. officinale had low alkane concentra-

Table 6. Correct allocation (\%) of marker profiles of plant species and concentrate with linear discriminant analysis ${ }^{1}$

\begin{tabular}{|c|c|c|c|c|c|c|c|c|}
\hline Marker group combination & LP & DG & OG & TR & TO & $\mathrm{OF}$ & Conc & Total \\
\hline LCFA & 50 & 100 & 50 & 100 & 100 & 75 & 100 & 81 \\
\hline $\mathrm{LCOH}$ & 75 & 100 & 100 & 100 & 100 & 100 & 100 & 96 \\
\hline$n$-alkanes $+\mathrm{LCOH}$ & 50 & 100 & 75 & 75 & 67 & 50 & 100 & 74 \\
\hline $\mathrm{LCFA}+\mathrm{LCOH}$ & 50 & 75 & 50 & 100 & 100 & 100 & 100 & 81 \\
\hline$n$-alkanes $+\mathrm{LCFA}+\mathrm{LCOH}$ & 25 & 0 & 0 & 0 & 0 & 25 & 33 & 12 \\
\hline
\end{tabular}

${ }^{1} \mathrm{LP}=$ Lolium perenne $; \mathrm{DG}=$ Dactylis glomerata $; \mathrm{OG}=$ other grass species; $\mathrm{TR}=$ Trifolium repens $; \mathrm{TO}=$ Taraxacum officinale $;$ OF $=$ other forb species; Conc = concentrate; LCFA = long-chain fatty acids; and LCOH = long-chain alcohols. 
tions, but achieved a 100\% correct assignment with alkanes alone. Long-chain fatty acids achieved a good differentiation of plant species, but no individual LCFA was identified that contributed most for differentiation. The concentration of LCFA in samples of $L$. perenne was similar to that of Ferreira et al. (2010), except $\mathrm{C}_{30}$ and $\mathrm{C}_{32} \mathrm{LCFA}$, which in the current study showed lower concentration. In contrast, concentrations of the LCFA with a CCL of $22,24,26$, and 28 in T. repens samples were higher in the current study compared with Ferreira et al. (2010) and those with a CCL of 30, 32, and 34 were in the same range. Environmental conditions, variety, and plant growth stage can influence the
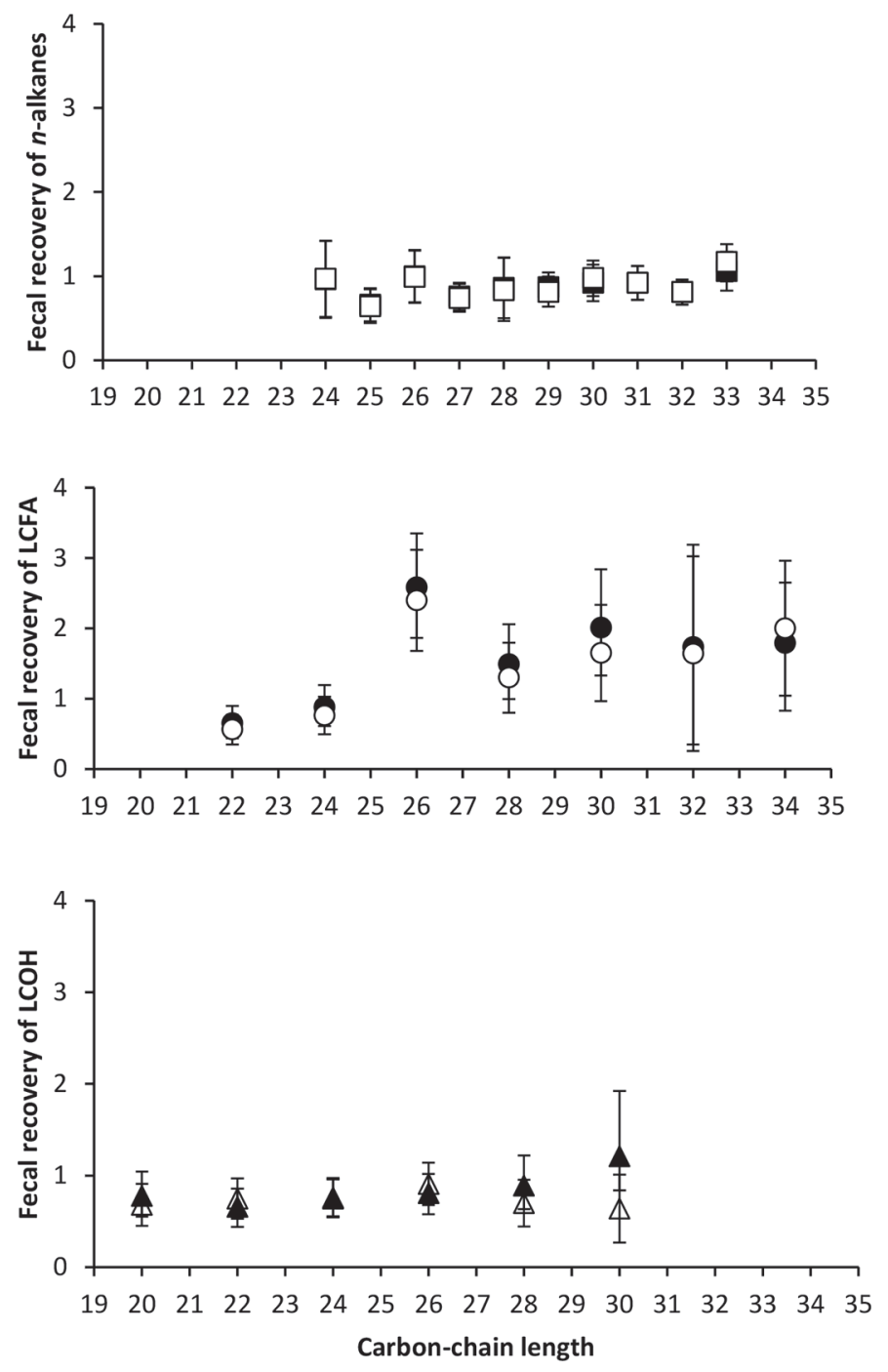

Figure 2. Calculated fecal recoveries of markers based on alkane concentration (1) and on botanical composition (2). $=$ fecal recovery 1 of $n$-alkanes; $\square=$ fecal recovery 2 of $n$-alkanes; $\bullet=$ fecal recovery 1 of long-chain fatty acids (LCFA); $\bigcirc=$ fecal recovery 2 of long-chain fatty acids; $\boldsymbol{\Delta}=$ fecal recovery 1 of long-chain alcohols $(\mathrm{LCOH}) ; \Delta=$ fecal recovery 2 of long-chain alcohols. Error bars indicate SD. concentration of plant wax markers. A comparison of samples from different locations and time is therefore problematic. The predominant $\mathrm{LCOH}$ for grass species are those with a CCL of 26 and 28 (Dove and Charmley, 2008; Ferreira et al., 2015), whereas the $\mathrm{C}_{30} \mathrm{LCOH}$ was dominant in $T$. repens, which is typical for clover (Dove and Charmley, 2008). However, the $\mathrm{C}_{24}$ and $\mathrm{C}_{26}$ $\mathrm{LCOH}$ contributed most to the accurate allocation in the current study. Labeling the concentrate with the $\mathrm{C}_{28}$ alkane seems to be sufficient for discrimination, and allocation also worked well with LCFA and LCOH without labeling. However, estimations of proportion of concentrate in the diet may be underestimated (Figure 3). Hameleers and Mayes (1998) did not consider the supplemented barley in diet composition calculations because of the low alkane concentration. Without labeling, grain-based concentrate, which has low alkane concentrations, may lead to difficulties in accurate estimation of the concentrate proportion in the diet (Charmley and Dove, 2007). The advantage of using labeled concentrate is the parallel assessment of DMI of the animals, as discussed in Dove and Charmley (2008).

\section{Fecal Recovery}

Estimation of FR of grazing animals is difficult as total fecal output, composition of plant species on pasture and precise pasture DMI estimation are required. An independent feeding experiment with housed animals and total feces collection is labor intense and expensive, and feed selection of cut herbage fed indoors might be different compared with selection behavior on pasture. Rectal grab samples collected once or twice daily provide a representative marker profile in the feces and are valid for estimating diet composition under field conditions (Dove and Charmley, 2008). Calculated FR based on the fixed $\mathrm{FR}$ of $\mathrm{Yb}$ led to appropriate results, at least for alkanes and LCOH. Further studies are necessary to investigate whether the methods for calculating FR are adequate and correlate to measured FR.

In previous studies, FR increased with increasing CCL for alkanes, LCFA, and LCOH (Dove and Charmley, 2008; Elwert et al., 2008; Ferreira et al., 2011). In the current study, all calculated FR tended to increase with CCL except the FR2 for LCOH. Similar to the study of Ferreira et al. (2009), no clear relationship was detected between alkane CCL and FR. A separate analysis of odd- and even-numbered alkanes indicated a linear increase for FR of odd-numbered alkanes and a curvilinear decrease for FR of even-numbered alkanes. Concentration of even-numbered alkanes is low compared with odd-numbered alkanes and low concentrations include more analytical uncertainties. The values of both calculated FR and their SD for LCFA were 
Table 7. Results of diet estimation validation with Aitchison distance

\begin{tabular}{lllc}
\hline Sequence & Marker combination ${ }^{1}$ & $\begin{array}{l}\text { Fecal } \\
\text { recovery }\end{array}$ & $\begin{array}{c}\text { Aitchison } \\
\text { distance }\end{array}$ \\
\hline 1 & $n$-alkanes + LCOH & FR1 & $0.368^{3}$ \\
2 & $n$-alkanes + LCOH & FR2 & 0.437 \\
3 & LCOH & FR2 & 0.447 \\
4 & $n$-alkanes + LCOH & FR0 & 0.458 \\
5 & LCOH & FR0 & 0.463 \\
6 & LCOH & FR2 & 0.474 \\
7 & $n$-alkanes + LCFA + LCOH & FR2 & 0.583 \\
8 & LCFA + LCOH & FR2 & 0.630 \\
9 & $n$-alkanes + LCFA + LCOH & FR1 & 0.637 \\
10 & $n$-alkanes + LCFA + LCOH & FR0 & 0.644 \\
11 & LCFA + LCOH & FR0 & 0.647 \\
12 & LCFA + LCOH & FR1 & 0.669 \\
13 & $n$-alkanes & FR0 & 0.680 \\
14 & $n$-alkanes & FR1 & 0.734 \\
15 & $n$-alkanes & FR2 & 0.809 \\
16 & $n$-alkanes + LCFA & FR0 & 1.060 \\
17 & LCFA & FR0 & 1.060 \\
18 & $n$-alkanes + LCFA & FR1 & 1.060 \\
19 & LCFA & FR1 & 1.060 \\
20 & $n$-alkanes + LCFA & FR2 & 1.060 \\
21 & LCFA & FR2 & 1.060 \\
\hline
\end{tabular}

${ }^{1} \mathrm{LCFA}=$ long-chain fatty acids. $\mathrm{LCOH}=$ long-chain alcohols.

${ }^{2} \mathrm{FR} 0=$ no correction for fecal recovery. FR 1 = mean fecal recovery calculated according to alkanes in herbage samples. FR2 = mean fecal recovery according to botanical composition analysis.

${ }^{3}$ Value for Aitchison distance of the marker combination alkanes + LCOH and FR1 differs significantly $(P<$ 0.001) from the value for Aitchison distance of marker combination alkanes and LCOH with FR2.

unrealistically high (up to 2.6) with the highest value for the LCFA with CCL of 26. The increase of both calculated FR occurred in a curvilinear way, as in the study of Ferreira et al. (2011). Equally, a high concen- tration of the LCFA with a CCL of 26 was observed in the study of Ferreira et al. (2011), although the value did not exceed 1.0. The current method of calculating FR did not work for LCFA as evidenced by unrealisti-

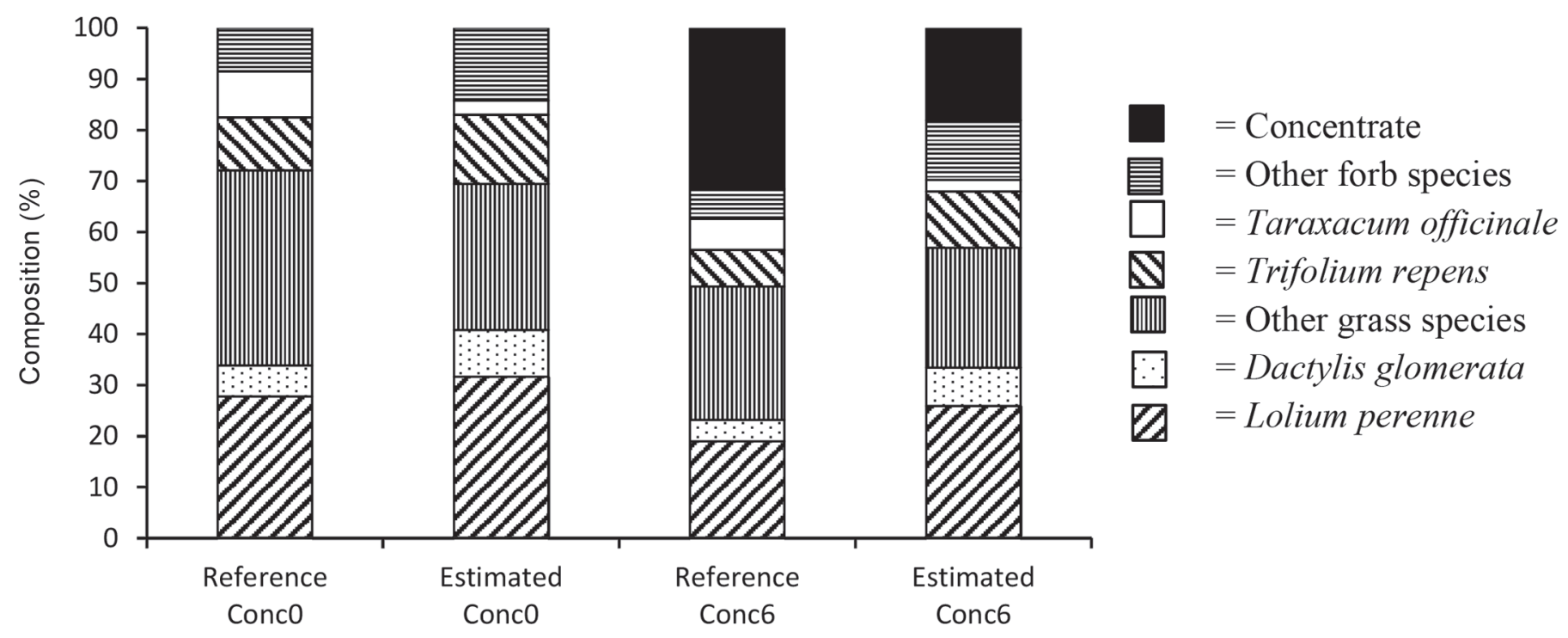

Figure 3. Diet composition assessed during manual plant species separation or estimated with "EatWhat" considering the combination of $n$ alkanes, long-chain alcohols, and fecal recovery, determined with alkane concentration in pasture and feces samples (FR1), with or without concentrate. Reference Conc0 = diet composition of nonsupplemented cows determined during manual plant species separation; Estimated Conc0 = estimated diet composition of nonsupplemented cows determined with "EatWhat"; Reference Conc6 = diet composition including concentrate of supplemented cows determined during manual plant species separation; Estimated Conc6 = estimated diet composition including concentrate of supplemented cows determined with "EatWhat." 
cally high values but, in contrast, calculated FR for alkanes and LCOH seemed to be appropriate. Measured LCFA in feces could partly originate from endogenous sources and peaks might not be completely pure (Ali et al., 2005). However, a subset of samples was tested using GC-MS and peaks of LCFA were identified without contamination of other FA components. Nevertheless, the LCFA concentration in feces may be overestimated leading to unrealistically high FR and resulting in inaccurate diet estimations. Both methods of calculating FR achieved similar results (taking into account the relation between the difference of the means to the $\mathrm{SD}$ ) for alkanes, LCFA and LCOH, except $\mathrm{C}_{28}$ and $\mathrm{C}_{30}$ $\mathrm{LCOH}$. The FR1 increased with increasing CCL in a linear way as recorded by Dove and Charmley (2008), but FR2 increased up to the $\mathrm{C}_{26} \mathrm{LCOH}$ and decreased with increasing CCL afterward. Furthermore, SD was high for the $\mathrm{LCOH}$ with a CCL of 30, especially for FR1. This may be related to different consumption of T. repens, which has high concentrations of $\mathrm{C}_{30} \mathrm{LCOH}$. Ruminant species may also have an effect on FR (Ferreira et al., 2011) as well as diet composition (Elwert et al., 2008; Ferreira et al., 2010), although others reported no effect of diet composition on FR (Ali et al., 2004; Dove and Charmley, 2008). Increasing digestibility of diet components decreased the FR of alkanes, which partly explained the differences in FR between diets in the study of Elwert et al. (2008). In accordance with Ferreira et al. (2015), diet estimation was more accurate with $\mathrm{FR}$ than without $\mathrm{FR}$, indicating that a correction of marker concentration in feces is recommended. The significant difference between the combinations of alkanes and $\mathrm{LCOH}$ with either FR1 or FR2 for diet estimation indicates that a correction of recoveries calculated with the alkanes (FR1) results in more precise diet estimation, at least for the combination of alkanes and LCOH. Probably, diet estimations with FR1 achieved better results as alkanes were also used to estimate botanical composition for calculating FR. The botanical composition assessed during manual separation of plant species for FR2 might be a more independent factor. Therefore, it is important that pasture is grazed evenly without systematic leftovers. This is difficult to ensure as cows avoid grazing around dung patches. Further studies with total fecal output collection would be necessary to confirm and improve the used methods for FR determination.

\section{Diet Composition Estimations}

Results of diet estimation with the program "EatWhat" (Dove and Moore, 1995) were compared using the Aitchison distance with the average botanical composition of pastures. Cows stayed on paddocks until an average postgrazing height of $56 \mathrm{~mm}$ in the first and $64 \mathrm{~mm}$ in the second period and thus, we can assume a consumption of all plants on pasture. This assumption was supported by visual evaluations. Regarding marker groups separately, LCOH achieved best results for diet estimation followed by results with alkanes and the poorest results were reached with LCFA, as in Ali et al. (2005). The best combination for diet estimation was alkanes and $\mathrm{LCOH}$ with a correction of FR, followed by $\mathrm{LCOH}$ alone. This is in agreement with Ferreira et al. (2015), where a combination of alkanes and $\mathrm{LCOH}$ improved accuracy of diet estimation compared with $\mathrm{LCOH}$ or alkanes alone. In our study, using $\mathrm{LCOH}$ alone achieved a more accurate diet estimation compared with any combination with LCFA or with a combination of all 3 marker groups.

The marker group combination of alkanes and LCFA resulted in a less accurate diet estimation compared with $\mathrm{LCOH}$ alone, which is contrary to results of Ferreira et al. (2011). Despite reasonable differentiation

Table 8. Results of diet estimation with most accurate marker combination (alkanes and long-chain alcohols with fecal recovery 1) and their effect on concentrate supplementation and cow strain ${ }^{1}$

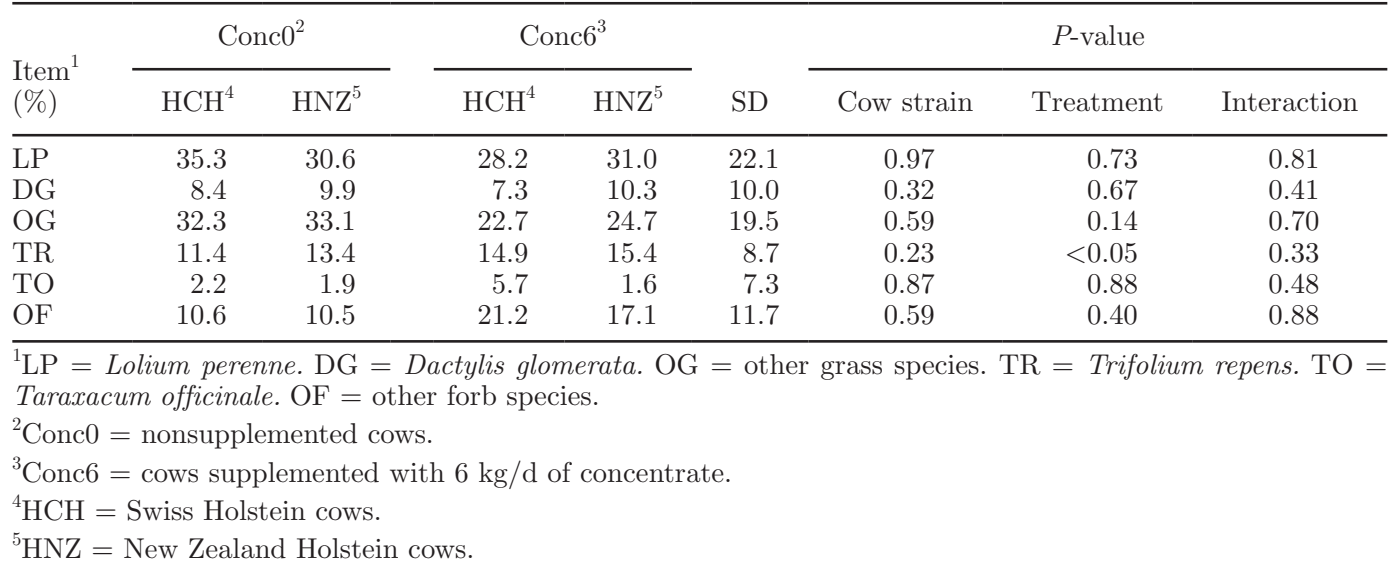


between plant species, diet estimation reached poor results with LCFA, as in Ali et al. (2005), indicating difficulties in the analysis of LCFA in feces. Thus, differentiation of marker profiles between plant species is essential, but does not guarantee reasonable results for diet estimation. Other factors, such as correction of FR or relation of patterns in plant species to patterns in feces influence the method of diet estimation. Mayes and Dove (2000) mentioned that markers with the highest concentration affected diet estimation more than lower marker concentration, particularly when least squares are used. Transforming to relative terms, weighting individual marker concentration or omitting certain markers according to individual analytical uncertainties, concentration levels, utility for discrimination, or variability within plant species might be useful for a better diet composition estimation (Mayes and Dove, 2000).

With the best marker combination (alkanes and LCOH with FR1), concentrate was identified as a part of diet composition but, the proportion was underestimated (Figure 3), which is in line with the results of Dove and Charmley (2008) who calculated FR as a grand mean of all treatments. On the other hand, herbage DMI might be underestimated resulting in higher percentage of concentrate in the diet. Average herbage DMI of $15 \mathrm{~kg} / \mathrm{d}$ for nonsupplemented cows seemed to be reasonable and is comparable to values presented in the review of Bargo et al. (2003). Higher herbage DMI (McCarthy et al., 2007) are possible as herbage DMI depends on intake capacity, milk production, and herbage offer (quality and quantity). Estimating DMI of grazing animals may contain difficulties (Thanner et al., 2014), but the double-alkane method was tested indoors (Berry et al., 2000) and outdoors (Bezabih et al., 2012), and considered to be accurate. Estimated percentage of $T$. officinale in the diet was lower compared with botanical composition, although dairy cows may prefer T. officinale over grass species (Lantinga et al., 2004). The underestimation might have resulted from low alkane concentrations of $T$. officinale, even though $\mathrm{LCOH}$ concentration was high. Low marker concentrations lead to difficulties in accurate diet composition estimation (Charmley and Dove, 2007). A reason for the overestimated portion of the group other forbs may be the heterogeneous composition of the group. Forb species differ in their morphological appearance, and a separate analysis of forb species, which are included in the group other forbs, may be necessary to test the variance of marker profiles between them and decide if a different grouping of the forbs is preferable. Differences between botanical composition on pasture and estimated diet composition might occur because of individual variation of cows' selection behavior. Com- pared with other studies where all cows received the same diet with the same composition, diet selection and preference may play a bigger role in grazing dairy cows.

\section{Differences Between Cow Strains and Effect of Concentrate Supplementation}

With the most accurate diet estimation (alkanes, $\mathrm{LCOH}$, and FR1), differences between the 2 cow strains and the effect of concentrate supplementation on diet selection have been investigated. Fedele et al. (1993) recorded differences of feed preference between 2 breeds of goats grazing on pasture. In the current experiment, similar diet selection between cow strains is in accordance with their similar grazing and rumination behavior. The concentrate supplementation had a similar effect on the milk production, milk composition, grazing time, herbage, and total DMI of grazing cows as in other studies [Bargo et al., 2003; McCarthy et al., 2007; C. Heublein, F. Dohme-Meier, K.-H. Südekum, R. M. Bruckmaier (Vetsuisse Faculty, Bern, Switzerland), S. Thanner (Agroscope, Posieux, Switzerland), and F. Schori, unpublished data]. Interestingly, current results indicate that supplemented grazing dairy cows apparently select different plant species for ingestion compared with nonsupplemented cows. The reasons for plant species selection and preference in ruminants are still unclear and several assumptions exist, such as balancing nutrient intake, maintaining rumen function, and avoiding toxins (Rutter, 2006). The assumption that dairy cows balance their nutrient intake, as shown for pigs (Lin and Patience, 2016) and poultry (Denbow and Cline, 2015), may fit with results of the current study, because cows supplemented with energy-rich concentrate had a higher amount of $T$. repens in their diet compared with nonsupplemented cows. As T. repens had higher content of $\mathrm{CP}$ and lower concentrations of WSC and ESC, supplemented cows may have tried to balance their diet. Results of Bach et al. (2012) indicate that lambs can balance their $\mathrm{CP}$ intake according to their requirements. Grain-based concentrate has high concentrations of highly fermentable carbohydrates (high concentration of starch), which causes a decline in rumen $\mathrm{pH}$ and increases the risk of cows becoming acidotic (Bramley et al., 2008). The decrease in milk fat concentration of supplemented cows indicated changes in rumen VFA profiles. Animals may select plant species to reduce the variation in ingesta composition as far as possible (Fedele et al., 1993) and might have reacted to supplementation of concentrate by avoiding plant species high in WSC concentration. Grazing cows and sheep exhibit a preference for clover over grass, but they prefer mixed diets, even when a diet of clover alone could match their nutrient requirements (Rutter, 
2006; Chapman et al., 2007). In contrast to the aforementioned studies, the current study took place on an organic, multispecies sward with a T. repens proportion of only $10 \%$, and thus, cows had to search more for preferred plant species. This assumption was supported by the results of similar physical activity between nonsupplemented and supplemented cows, although grazing time was significantly lower for supplemented cows. On the other hand, weather conditions in the first measurement period may have precluded supplemented cows lying down for long periods. Supplemented cows were probably more quickly satiated with a lower motivation to graze, which is supported by results of lower grazing time and lower mastication rate, but higher motivation to search for palatable plant species. Fasting sheep spend less time eating clover than L. perenne (Newman et al., 1994), indicating that fasting probably provokes a higher feeding drive, which results in longer grazing time and less selection. More research is needed to explore whether ruminants are able to select plant species to match their nutrient demand and which signals lead them to select. If other studies confirm that supplemented cows change their diet selection to balance carbohydrates and protein in the diet and to reduce the load of rapidly fermented carbohydrates, sward composition could be better adapted to the needs of the ruminants, for example, by increasing the percentage of $T$. repens of pasture DM. This may therefore increase efficiency.

\section{CONCLUSIONS}

The results of our study indicate that the diet selection of dairy cows under grazing condition can be estimated with plant wax markers. For the differentiation of plant species, $\mathrm{LCOH}$ performed best and the combination of all 3 marker groups achieved the worst differentiation. Diet estimation with LCFA alone or in combination gave poor results. Analytical difficulties concerning LCFA in feces might create uncertainties in the estimation of diet selection. The calculated FR relative to $\mathrm{Yb}$ gave mostly realistic results, but further validation is required. Using calculated FR instead of experimental measured ones would be time-saving, less expensive, and applicable for field work. The marker group combination alkanes and LCOH with FR1 achieved the most accurate results for diet composition estimation and provided evidence that $\mathrm{HCH}$ and $\mathrm{HNZ}$ cows had a similar diet selection behavior, and that concentrate supplementation influenced diet selection of grazing dairy cows. The knowledge of diet selection and foraging behavior may allow optimization of the offer (herbage) to the demands of the cows, which is expected to improve animal health, welfare, and efficiency.

\section{ACKNOWLEDGMENTS}

This study was funded by the AGFF (Zurich, Switzerland) research fund and the Fondation Sur-la-Croix (Basel, Switzerland). The authors gratefully acknowledge the help afforded to them by the staff of the farm "Ferme École de Sorens" and S. Thanner (Agroscope, Posieux, Switzerland) for assistance with the cows during experiment. We thank the staff of Agroscope in Posieux and F. Keay of Leeds University for assistance in the laboratory analysis and W. Luginbühl (Chemstat, Bern, Switzerland) for statistical advice.

\section{REFERENCES}

Agroscope. 2013. Fütterungsempfehlungen und Nährwerttabellen für Wiederkäuer (Grünes Buch). Online ed. Forschungsanstalt Agroscope Liebefeld-Posieux ALP, Posieux, Switzerland.

Aitchison, J., C. Barceló-Vidal, J. A. Martín-Fernández, and V. Pawlowsky-Glahn. 2000. Logratio analysis and compositional distance. Math. Geol. 32:271-275.

Ali, H. A. M., R. W. Mayes, B. L. Hector, A. K. Verma, and E. R. Ørskov. 2005. The possible use of n-alkanes, long-chain fatty alcohols and long-chain fatty acids as markers in studies of the botanical composition of the diet of free-ranging herbivores. J. Agric. Sci. 143:85-95. https://doi.org/10.1017/S0021859605004958.

Ali, H. A. M., R. W. Mayes, C. S. Lamb, B. L. Hector, A. K. Verma, and E. R. Ørskov. 2004. The potential of long-chain fatty alcohols and long-chain fatty acids as diet composition markers: Development of methods for quantitative analysis and faecal recoveries of these compounds in sheep fed mixed diets. J. Agric. Sci. 142:71-78. https://doi.org/10.1017/S0021859604004034.

AOAC International. 1995. Official Methods of Analysis. 16th ed. AOAC International, Arlington, VA.

Bach, A., J. J. Villalba, and I. R. Ipharraguerre. 2012. Interactions between mild nutrient imbalance and taste preferences in young ruminants. J. Anim. Sci. 90:1015-1025. https://doi.org/10.2527/ jas.2011-4176.

Bargo, F., L. D. Muller, E. S. Kolver, and J. E. Delahoy. 2003. Invited review: Production and digestion of supplemented dairy cows on pasture. J. Dairy Sci. 86:1-42. https://doi.org/10.3168/jds.S00220302(03)73581-4.

Berry, N. R., M. R. L. Scheeder, F. Sutter, T. F. Kröber, and M. Kreuzer. 2000. The accuracy of intake estimation based on the use of alkane controlled-release capsules and faeces grab sampling in cows. Ann. Zootech. 49:3-13. https://doi.org/10.1051/animres:2000104.

Bezabih, M., W. F. Pellikaan, A. Tolera, and W. H. Hendriks. 2012. Estimation of feed intake and digestibility in cattle consuming low-quality tropical roughage diets using molasses-based n-alkane bolus. Anim. Feed Sci. Technol. 177:161-171. https://doi. org/10.1016/j.anifeedsci.2012.08.014.

Boland, H. T., G. Scaglia, D. R. Notter, A. J. Rook, W. S. Swecker, and A. O. Abaye. 2012. Diet composition and dry matter intake of beef steers grazing tall fescue and alfalfa. Crop Sci. 52:2817-2825. https://doi.org/10.2135/cropsci2011.12.0638.

Bramley, E., I. J. Lean, W. J. Fulkerson, M. A. Stevenson, A. R. Rabiee, and N. D. Costa. 2008. The definition of acidosis in dairy herds predominantly fed on pasture and concentrates. J. Dairy Sci. 91:308-321. https://doi.org/10.3168/jds.2006-601.

Bush, R. T., and F. A. McInerney. 2013. Leaf wax n-alkane distributions in and across modern plants: Implications for paleoecology and chemotaxonomy. Geochim. Cosmochim. Acta 117:161-179. 
Chapman, D. F., A. J. Parsons, G. P. Cosgrove, D. J. Barker, D. M. Marotti, K. J. Venning, S. M. Rutter, J. Hill, and A. N. Thompson. 2007. Impacts of spatial patterns in pasture on animal grazing behavior, intake, and performance. Crop Sci. 47:399-415. https:// doi.org/10.2135/cropsci2006.01.0036.

Charmley, E., and H. Dove. 2007. Using plant wax markers to estimate diet composition and intakes of mixed forages in sheep by feeding a known amount of alkane-labelled supplement. Aust. J. Agric. Res. 58:1215-1225. https://doi.org/10.1071/AR07187.

Denbow, D. M., and M. A. Cline. 2015. Intake regulation. Pages 469485 in Sturkie's Avian Physiology. Vol. 6. C. G. Scanes, ed. Academic Press, London, UK

Dove, H., and E. Charmley. 2008. Using the alkanes and long-chain alcohols of plant cuticular wax to estimate diet composition and the intakes of mixed forages in sheep consuming a known amount of alkane-labelled supplement. Animal 2:1474-1485. https://doi. org/10.1017/S1751731108002735.

Dove, H., and R. W. Mayes. 1991. The use of plant wax alkanes as marker substances in studies of the nutrition of herbivores: A review. Aust. J. Agric. Res. 42:913-952.

Dove, H., and R. W. Mayes. 2006. Protocol for the analysis of nalkanes and other plant-wax compounds and for their use as markers for quantifying the nutrient supply of large mammalian herbivores. Nat. Protoc. 1:1680-1697. https://doi.org/10.1038/ nprot.2006.225.

Dove, H., R. W. Mayes, and M. Freer. 1996. Effects of species, plant part, and plant age on the n-alkane concentrations in the cuticular wax of pasture plants. Aust. J. Agric. Res. 47:1333-1347.

Dove, H., and A. D. Moore. 1995. Using a least-squares optimization procedure to estimate botanical composition based on the alkanes of plant cuticular wax. Aust. J. Agric. Res. 46:1535-1544.

Elwert, C., H. Dove, and M. Rodehutscord. 2008. Faecal alkane recoveries from multi-component diets and effects on estimates of diet composition in sheep. Animal 2:125-134. https://doi.org/10.1017/ S1751731107000900.

Fedele, V., M. Pizzillo, S. Claps, P. Morand-Fehr, and R. Rubino. 1993. Grazing behavior and diet selection of goats on native pasture in Southern Italy. Small Rumin. Res. 11:305-322. https://doi. org/10.1016/0921-4488(93)90002-Y

Ferreira, L. M. M., S. Carvalho, V. Falco, R. Celaya, U. García, A. S. Santos, M. A. M. Rodrigues, and K. Osoro. 2009. Assessment of very long-chain fatty acids as complementary or alternative natural fecal markers to n-alkanes for estimating diet composition of goats feeding on mixed diets. J. Anim. Sci. 87:2732-2745. https:// doi.org/10.2527/jas.2008-1718.

Ferreira, L. M. M., R. Celaya, V. Falco, M. Oliván, A. S. Santos, C. Guedes, M. A. M. Rodrigues, and K. Osoro. 2010. Evaluation of very long-chain fatty acids and n-alkane epicuticular compounds as markers for estimating diet composition of sheep fed heathland vegetation species. Anim. Feed Sci. Technol. 156:75-88. https:// doi.org/10.1016/j.anifeedsci.2010.01.007.

Ferreira, L. M. M., R. Celaya, A. S. Santos, V. Falco, C. Guedes, M. A. M. Rodrigues, and K. Osoro. 2011. The utilization of long-chain fatty acids as markers for diet composition estimates in ruminants: Effects of animal species, diet composition and marker combination. Grass Forage Sci. 66:183-195. https://doi.org/10.1111/ j.1365-2494.2010.00774.x.

Ferreira, L. M. M., R. Celaya, A. S. Santos, R. W. Mayes, M. A. M. Rodrigues, and K. Osoro. 2015. Application of long-chain alcohols as diet-composition markers in sheep fed on grass-white clover and heather-gorse plant species. Grass Forage Sci. 70:30-43. https:// doi.org/10.1111/gfs.12083.

Gedir, J. V., and R. J. Hudson. 2000. Seasonal intake determination in reproductive wapiti hinds (Cervus elaphus canadensis) using n-alkane markers. Can. J. Anim. Sci. 80:137-144. https://doi. org/10.4141/A99-042.

Graf, C. M., M. Kreuzer, and F. Dohme. 2005. Effects of supplemental hay and corn silage versus full-time grazing on ruminal $\mathrm{pH}$ and chewing activity of dairy cows. J. Dairy Sci. 88:711-725.
Hall, M. B., W. H. Hoover, J. P. Jennings, and T. K. Miller Webster. 1999. A method for partitioning neutral detergent soluble carbohydrates. J. Sci. Food Agric. 79:2079-2086.

Hameleers, A., and R. W. Mayes. 1998. The use of n-alkanes to estimate herbage intake and diet composition by dairy cows offered a perennial ryegrass/white clover mixture. Grass Forage Sci. 53:164169. https://doi.org/10.1046/j.1365-2494.1998.5320164.x.

International Dairy Federation. 2000. Determination of milk fat, protein and lactose content. Guide for the operation of mid-infra-red instruments. IDF Standard method No. 141C, Brussels, Belgium.

International Dairy Federation. 2004. Milk. Determination of urea content. Enzymatic method using difference in pH. IDF Standard method No. 195, Brussels, Belgium.

ISO (International Organization for Standardization). 2000. Animal feeding stuffs-Determination of starch content-Polarimetric method. ISO, Geneva, Switzerland.

Ivins, J. D. 1952. The relative palatability of herbage plants. Grass Forage Sci. 7:43-54. https://doi.org/10.1111/j.1365-2494.1952. tb01302.x.

Koller, M. 2015. robustlmm: Robust Linear Mixed Effects Models. R package version 1.7-2. Accessed Apr 10, 2015. http://CRAN.Rproject.org $/$ package $=$ robustlmm.

Lantinga, E. A., J. H. Neuteboom, and J. A. C. Meijs. 2004. Sward methods. Pages $23-52$ in Herbage Intake Handbook. Vol. 2. P. D. Penning, ed. The British Grassland Society, Reading, UK.

Lin, L. J., X. Y. Zhu, C. Jiang, H. L. Luo, H. Wang, Y. J. Zhang, and F. Z. Hong. 2012. The potential use of n-alkanes, long-chain alcohols and long-chain fatty acids as diet composition markers: Indoor validation with sheep and herbage species from the rangeland of Inner Mongolia of China. Animal 6:449-458. https://doi. org $/ 10.1017 /$ S1751731111001765.

Lin, Q., and J. F. Patience. 2016. Factors involved in the regulation of feed and energy intake of pigs. Anim. Feed Sci. Technol. https:// doi.org/10.1016/j.anifeedsci.2016.01.001.

Lüscher, A., I. Mueller-Harvey, J. F. Soussana, R. M. Rees, and J. L. Peyraud. 2014. Potential of legume-based grassland-livestock systems in Europe: A review. Grass Forage Sci. 69:206-228. https:// doi.org/10.1111/gfs.12124.

Martín-Fernández, J. A., C. Barceló-Vidal, and V. Pawlowsky-Glahn. 2003. Dealing with zeros and missing values in compositional data sets using nonparametric imputation. Math. Geol. 35:253-278. https://doi.org/10.1023/A:1023866030544.

Mayes, R. W., and H. Dove. 2000. Measurement of dietary nutrient intake in free-ranging mammalian herbivores. Nutr. Res. Rev. 13:107-138.

Mayes, R. W., C. S. Lamb, and P. M. Colgrove. 1986. The use of dosed and herbage n-alkanes as markers for the determination of herbage intake. J. Agric. Sci. 107:161-170. https://doi.org/10.1017/ S0021859600066910.

McCarthy, S., B. Horan, M. Rath, M. Linnane, P. O'Connor, and P. Dillon. 2007. The influence of strain of Holstein-Friesian dairy cow and pasture-based feeding system on grazing behaviour, intake and milk production. Grass Forage Sci. 62:13-26. https://doi. org/10.1111/j.1365-2494.2007.00557.x.

Mertens, D. R. 2002. Gravimetric determination of amylase-treated neutral detergent fiber in feeds with refluxing in beakers or crucibles: Collaborative study. J. AOAC Int. 85:1217-1240.

Newman, J. A., P. D. Penning, A. J. Parsons, A. Harvey, and R. J. Orr. 1994. Fasting affects intake behaviour and diet preference of grazing sheep. Anim. Behav. 47:185-193. https://doi.org/10.1006/ anbe.1994.1021.

Peiretti, P. G., G. Meineri, N. Miraglia, M. Mucciarelli, and D. Bergero. 2006. Intake and apparent digestibility of hay or hay plus concentrate diets determined in horses by the total collection of feces and n-alkanes as internal markers. Livest. Sci. 100:189-194. https://doi.org/10.1016/j.livprodsci.2005.08.016.

Piccand, V., E. Cutullic, S. Meier, F. Schori, P. L. Kunz, J. R. Roche, and P. Thomet. 2013. Production and reproduction of Fleckvieh, Brown Swiss, and 2 strains of Holstein-Friesian cows in a pasturebased, seasonal-calving dairy system. J. Dairy Sci. 96:5352-5363. 
R Core Team. 2012. R: A language and environment for statistical computing. R Foundation for Statistical Computing, Vienna, Austria. Accessed Apr 10, 2015. http://www.R-project.org/

Rutter, S. M. 2006. Diet preference for grass and legumes in freeranging domestic sheep and cattle: Current theory and future application. Am. Behav. Sci. 97:17-35. https://doi.org/10.1016/j. applanim.2005.11.016.

Schori, F., S. Darms, and A. Münger. 2012. Diet selection under full grazing of two Holstein strains in organic farming. Pages 276-278 in Proceedings of the 24th General Meeting of the EGF, Lublin, Poland.

Spehn, E. M., A. Hector, J. Joshi, M. Scherer-Lorenzen, B. Schmid, E. Bazeley-White, C. Beierkuhnlein, M. C. Caldeira, M. Diemer, P. G. Dimitrakopoulos, J. A. Finn, H. Freitas, P. S. Giller, J. Good, R. Harris, P. Högberg, K. Huss-Danell, A. Jumpponen, J. Koricheva, P. W. Leadley, M. Loreau, A. Minns, C. P. H. Mulder, G. O'Donovan, S. J. Otway, C. Palmborg, J. S. Pereira, A. B. Pfisterer, A. Prinz, D. J. Read, E.-D. Schulze, A.-S. D. Siamantziouras, A. C. Terry, A. Y. Troumbis, F. I. Woodward, S. Yachi, and J. H. Lawton. 2005. Ecosystem effects on biodiversity manipulations in European grasslands. Ecol. Monogr. 75:37-63. https://doi. org $/ 10.1890 / 03-4101$.
Thanner, S., F. Schori, R. M. Bruckmaier, and F. Dohme-Meier. 2014 Grazing behaviour, physical activity and metabolic profile of two Holstein strains in an organic grazing system. J. Anim. Physiol. Anim. Nutr. (Berl.) 98:1143-1153. https://doi.org/10.1111/ jpn. 12172

van den Boogaart, K. G., R. Tolosana, and M. Bren. 2014. Compositions: Compositional Data Analysis. R-package version 1.40-1. Accessed Apr. 10, 2015. http://CRAN.R-project.org/ package $=$ compositions.

VDLUFA. 2012. Handbuch der Landwirtschaftlichen Versuchs- und Untersuchungsmethodik (VDLUFA-Methodenbuch), Bd. III: Die Chemische Untersuchung von Futtermitteln. VDLUFA-Verlag, Darmstadt, Germany.

Villalba, J. J., F. D. Provenza, F. Catanese, and R. A. Distel. 2015. Understanding and manipulating diet choice in grazing animals. Anim. Prod. Sci. 55:261-271. https://doi.org/10.1071/AN14449.

Wilson, J. 2013. PCS: Calculate the probability of correct selection (PCS). R-package version 1.2. Accessed Apr. 10, 2015. https:// cran.r-project.org. 